relief measures. Economic Times. 2020 Mar 26 [cited 2020 Apr 30]. Available from: https://bfsi.economictimes.indiatimes.com/news/ policy/fm-reinstates-nari-tu-narayani-dictum-announces-covid-19relief-measures/74828261

19. Mohammad I. Rajasthan announces 2,000 crore package for poor during lockdown. Hindu. 2020 Mar 23 [cited 2020 Apr 30]. Available from: https://www.thehindu.com/news/national/other-states/ rajasthan-announces-2000-crore-package-for-poor-during-lockdown/ article31145419.ece

20. Goswami R. Rajasthan govt identify migrant workers, distribute them free ration for 2 months. Hindustan Times. 2020 May 22 [cited 2020 Jun 8]. Available from: https://www.hindustantimes.com/india-news/ rajasthan-govt-identify-migrant-workers-distribute-them-free-rationfor-2-months/story-6DLPKRaZw1tt3sNilbv1CK.html

21. Kumar R, Yadav P. Why women, children In Rajasthan's tribal belts are facing hunger. India Spend. 2020 May 30. [cited 2020 June 8]. Available from: https://www.indiaspend.com/why-women-children-inrajasthans-tribal-belts-are-facing-hunger/

22. Aajeevika Bureau. Household survey of 3000 families conducted in six blocks of Rajasthan, 2019-2020 (unpublished).

23. Tripathi A, Sagar A. Ujjwala, V2.0: What should be done next? Policy brief. New Delhi:, Collaborative Clean Air Policy Centre; 2019 Jun [cited 2020 Jun 8]. Available from: https://static1.squarespace.com/ static/59f2a2038a02c746600f6bbb/t/5d0503a7562f010001cc37 3f/1560609704122/Ujjwala+V2.0+Jun+19b.pdf

24. Kulkarni R. Covid lockdown: In rural India, banking correspondents bring cash, emotional support to the doorstep. Scroll. 2020 Apr 30 [cited 2020 May 18]. Available from : https://scroll.in/article/960599/ covid-lockdown-in-rural-india-banking-correspondents-bring-cashemotional-support-to-the-doorstep

25. REACH. A Rapid Assessment of Gender and Tuberculosis in India (2018). 2018 [cited 2020 Apr 30]. Available from: http://www.stoptb.org/assets/ documents/communities/CRG/TB\%20Gender\%20Assessment $\% 20$ India.pdf

26. India Today Web Desk. New lockdown guidelines: Govt says MGNREGA works allowed from April 20. India Today. 2020 April 15 [cited 2020 May 18]. Available from: https://www.indiatoday.in/india/story/ new-lockdown-guidelines-govt-says-mgnrega-works-allowed-fromapril-20-1667114-2020-04-15

27. Agarwal K. COVID-19 Lockdown: In April, MGNREGA work crashed to lowest in 7 years. Wire. 2020 May 1 [cited 2020 Jun 8]. Available from: https://thewire.in/labour/covid-19-lockdown-mgnrega

28. Chauhan C. 3.5 million new enrolments under MGNREGA, as 'distressed' workers return to villages. Hindustan Times. 2020 May 22 [cited 2020 Jun 8]. Available from: https://www.hindustantimes.com/india-news/35-million-new-enrolments-under-mgnrega-as-distressed-workers-
return-to-villages/story-aDJHYz0vz1tSeLlelhVT7l.html

29. Jayaram N, Mehrotra R. Marooned in the city. Frontline. 2020 Apr 24 [cited $2020 \mathrm{Apr}$ 30]. Available from: https://frontline.thehindu.com/ cover-story/article31257591.ece

30. Naidu S.C. Domestic labour and female labour force participation: Adding a piece to the puzzle. Econ Pol Wkly. 2016 Nov 5 [cited 2020 Apr 30]; 51(44- 45): 101-8 . Available from: https://www.epw.in/ journal/2016/44-45/special-articles/domestic-labour-and-femalelabour-force-participation.html

31. Salve P. 71 million single women, 39\% rise over a decade. India Spend. 2015 Nov14. [cited 2020 Jun 8]. Available from: https://archive. indiaspend.com/cover-story/71-million-single-women-39-rise-over-adecade-54854

32. Agarwal $\mathrm{Di}$, Dhurve P. Dola Ram's long and locked-down road home. People's Archive of Rural India. 2020 Apr 30 [cited 2020 June 8]. Available from: https://ruralindiaonline.org/articles/dola-rams-long-and-lockeddown-road-home/

33. World Health Organization. COVID-19 and violence against women. What the health sector/system can do. Geneva: WHO; 2020 Apr 07 [cited 2020 Apr 30]. Available from: https://apps.who.int/iris/bitstream/ handle/10665/331699/WHO-SRH-20.04-eng.pdf?ua=1

34. Press Trust of India. India witnesses steep rise in crime against women amid lockdown, 587 complaints received: NCW. Economic Times. 2020 Apr 17 [cited 2020 Apr 30]. Available from: https://economictimes. indiatimes.com/news/politics-and-nation/india-witnesses-steep-risein-crime-against-women-amid-lockdown-587-complaints-receivedncw/articleshow/75201412.cms

35. Rajput M, Dhurve P. Corona maane bhook se marne ki bimari. Dakshini Rajasthan ki Adivasi mahilayein aisa kyun sochti hain? [Corona means dying of hunger: Why do the Adivasi women of southern Rajasthan think like this?]. Junputh. 2020 May 19 [cited 2020 June 8]. Available from: https://junputh.com/open-space/stories-of-lockdown-violenceon-tribal-women-of-south-rajasthan/

36. Sanghera T. Wide gender gap in mobile phone access is hurting India's women. India Spend. 2018 Nov 1 [cited 2020 May 18]. Available from: https://www.indiaspend.com/wide-gender-gap-in-mobile-phoneaccess-is-hurting-indias-women/

37. Indian Institute for Population Sciences. National Family Health Survey (NFHS 4) Rajasthan: Main Report. 2015-16.2017 Oct [cited 2020 May 18]. Available from: http://rchiips.org/nfhs/rajasthan.shtml

38. Ministry of Labour and Employment, Govt of India. Expert committee submits its report on determining methodology for fixing national minimum wage. New Delhi: MoLE; 2019 Feb 14 [cited 2020 May 18]. Available from: https://pib.gov.in/PressReleasePage. aspx?PRID $=1564590$

\title{
Burnout among healthcare providers during COVID-19: Challenges and evidence-based interventions
}

\section{ABIDA SULTANA, RACHIT SHARMA, MD MAHBUB HOSSAIN, SUDIP BHATTACHARYA, NEETU PUROHIT}

Authors: Abida Sultana (corresponding author - a.sultana21@outlook. com), Gazi Medical College, Khulna, BANGLADESH; Rachit Sharma (drrachitsharma09@gmail.com), The INCLEN Trust, New Delhi, INDIA; Md Mahbub Hossain (mhossain@tamu.edu), Texas A\&M School of Public Health, TX 77843, USA; Sudip Bhattacharya (drsudip81@gmail.com), Department of Community Medicine, HIMS, Dehradun, INDIA; Neetu Purohit (neetu@iihmr.edu.in), The IIHMR University, Jaipur, Rajasthan, INDIA.

To cite: Sultana A, Sharma R, Hossain MM, Bhattacharya S, Purohit N. Burnout among healthcare providers during Covid-19: Challenges and evidencebased interventions. Indian J Med Ethics. 2020 Oct-Dec;5(4) NS: 308-11. DOI: 10.20529/IJME.2020.73.

Published online on July 4,2020.

Peer Reviewer:Dheeraj Kattula

○ Indian Journal of Medical Ethics 2020

\section{Abstract}

Burnout is a major occupational problem among healthcare providers, especially during the Covid-19 pandemic. The frontline health workforce is experiencing a high workload and multiple psychosocial stressors which may affect their mental and emotional health, leading to burnout symptoms. Moreover, sleep deprivation and a critical lack of psychosocial support may aggravate such symptoms amidst Covid-19. From an ethical viewpoint, healthcare providers may experience moral distress while safeguarding patient welfare and autonomy. Moreover, social injustice and structural inequities may affect 
their emotional health while tackling a high volume of new cases and mortality. Global evidence indicates the need for adopting multipronged evidence-based approaches to address burnout during this pandemic, which may include increasing the awareness of work-related stress and burnout, promoting mindfulness and self-care practices for promoting mental wellbeing, ensuring optimal mental health services, using digital technologies to address workplace stress and deliver mental health interventions, and improving organisational policies and practices focusing on burnout among healthcare providers.

Keywords: Burnout, occupational stress, coronavirus disease, Covid-19, health workforce, occupational health, health policy

\section{Introduction}

Professional burnout is a major global health concern among physicians, nurses, and other healthcare providers (1-3). Healthcare providers often experience high workload, strict organisational regulations, and insufficient time to cope with occupational challenges, a rapidly evolving knowledge base, and a lack of interpersonal support in everyday life (3). These challenges often lead to "emotional exhaustion," where a person feels overwhelmed and lacks the energy to accomplish a task. "Depersonalisation" may follow emotional exhaustion, where a person may cynically treat others as objects. Also, a diminished sense of self-efficacy and competence affect the emotional wellbeing of an individual. Thus, emotional exhaustion, depersonalisation, and a decreased sense of personal accomplishments characterise burnout, which is a growing concern for the healthcare community globally. A systematic review found burnout scores for emotional exhaustion ranged from $31 \%$ to $54.3 \%$, depersonalisation $17.4 \%$ to $44.5 \%$, and low personal accomplishment $6 \%$ to $39.6 \%$ among doctors in the UK (1). Another meta-analytic review found $11.23 \%$ of participating nurses experienced burnout globally (2). Such a high burden of burnout is likely to increase during the coronavirus disease (Covid-19) pandemic, where healthcare providers in most health systems face a high workload. Recent media reports also highlight this critical challenge $(4,5)$, which may affect healthcare values during this pandemic, necessitating ethical discourse on burnout. This article discusses the current scenario of burnout among healthcare providers during Covid-19, key ethical implications, and highlights potential strategies to address them.

\section{Psychosocial stressors during Covid-19 and a high burden of burnout}

A wide range of occupational stressors is associated with Covid-19. Large numbers of potential cases arriving in hospitals and constraining institutional capacities result in additional workplace-related stress, especially among emergency care providers. Moreover, working hard during emergencies or stressful conditions often comes with sleep deprivation, increasing the risks of burnout (6). A Canadian Medical Association study found emergency physicians are almost three times as likely to suffer depression compared to the national average while one in seven physicians had suicidal thoughts in normal times (7). Other studies have shown that healthcare providers working in infection control or among isolated or quarantined individuals are likely to experience multiple mental health problems (8). In addition, many of the existing providers are withdrawn or suggested selfisolation after working on Covid-19 cases (9). Such concurrent experience of high workload, the fear of being infected, and disrupted social support during isolation or quarantine are critical factors that may influence burnout and associated psychosocial health outcomes (8). Many other challenges like the lack of personal protective equipment, may crucially affect mental health and wellbeing among healthcare providers $(10,11)$. Additionally, they are sometimes stigmatised as possible carriers of the virus by members of the public, as reported in several news media $(12,13)$, increasing stress and hastening burnout. These are some glimpses of the difficulties experienced by frontline health workers, though the true psychosocial and epidemiological burden of burnout during Covid-19 is largely underreported.

\section{Perspectives on healthcare ethics}

The ongoing pandemic has created several unique ethical dilemmas for healthcare workers:

- While healthcare providers have the autonomy to decide on working in a healthcare organisation based on perceived safety or risks, they also have a shared responsibility to serve people in a humanitarian crisis. In a pandemic, ethical values, including the autonomy of providers to make decisions may be curtailed, thus affecting their psychological and emotional health (14).

- Moral distress has been identified across the scholarly community as a root cause of burnout in healthcare providers (14-16). Dzeng and Wachter argue that healthcare providers who struggle to balance institutional priorities with the best interests of patients are highly vulnerable to moral dissonance (14). Such distress would be aggravated when serving large numbers of patients within limited institutional capacities.

- Patient autonomy and welfare remain core ethical concepts in medical practice which are critically affected in case of patients on ventilator support (16). With limited therapeutic options for Covid-19, a physician may face moral uncertainly while deciding on treatment, with the patient unable to participate in decision-making due to a critical health condition. Earlier studies have established that intensive care providers often experience such dilemmas and experience more burnout in their careers $(15,16)$.

- News reports, several from developed nations, highlight that marginalised populations, including racial and ethnic minorities, are more likely to get infected and have adverse healthcare access as well as outcomes (17). This can be profoundly challenging for those struggling to cope with rapidly increasing new cases and fatalities every day of this pandemic. Despite their dedication, structural inequities may affect the emotional health of healthcare providers 
(14), and lead to helplessness in the face of challenges closely related to social justice and human rights.

- Lastly, ethical concerns can be uniquely different in diverse settings, which calls for a careful assessment of context-specific issues and their ethical implications through designated ethical committees in the respective institutions (18). Moreover, ongoing public health emergencies like Covid-19 may not provide adequate scope for analysing the most ethical approaches, as the institutions are stressed by the additional volume of Covid-19 patients alongside regular patients. Such challenges remain underexplored in the available literature, and this necessitates further ethical assessment and discourse.

The current scenario provides an adequate basis to acknowledge critical gaps in the context of Covid-19 that may increase burnout among healthcare providers, with the ethical implications stated above. Therefore, drawing insights from evidence-based approaches may help in mitigating burnout, and help healthcare providers to overcome the ethical challenges, manage their stress, and fulfil their professional responsibilities satisfactorily.

\section{Potential strategies for addressing burnout in healthcare providers during COVID-19}

Some steps based on multipronged evidence-based approaches which could address stress and prevent burnout during this pandemic are:

\section{Making healthcare providers aware of potential burnout}

Burnout can be prevented if the providers are made aware of the risks and prepared for potential occupational stress. Such awareness can reduce the stigma linked to mental health conditions like burnout and help in developing resilience. For example, a study on Ebola response found that situational awareness alongside other preventive measures improved psychological resilience among healthcare providers (19). A meta-analysis found the correlation between resilience and burnout among Iranian nurses was -0.57 (95\% confidence interval [Cl]:-0.354-0.726) (20). This evidence highlights the role of increasing awareness and adopting strategies to empower healthcare providers during Covid-19.

\section{Promoting positive mental health: Mindfulness and self-care practices}

Positive mental health can prevent work-related stress and burnout, which should be promoted among healthcare providers during the pandemic. Several strategies include decreasing the workload, improving work schedules, promoting self-management, initiating mindfulness-based stress reduction and mental health promotion activities for reducing the risks of burnout (21). A meta-analysis of 17 studies among 632 nurses had found lower standardised mean difference for emotional exhaustion (1.32; 95\% Cl: -9.41-6.78) and depersonalisation $(1.91 ; 95 \% \mathrm{Cl}:-4.50-0.68)$, and a higher mean difference for personal accomplishment $(2.12 ; 95 \% \mathrm{Cl}$ :
-9.91-14.14) (22). During Covid-19, healthcare organisations and professional entities may facilitate mindfulness-based interventions and self-management exercises promoting mental health and preventing potential burnout.

\section{Ensuring the availability of mental health services}

Providing mental health services can be challenging during Covid-19, but such opportunities should be explored. Potential strategies to improve access to mental health services may include involving mental health experts in multidisciplinary Covid-19 teams, who may provide services or refer healthcare workers showing symptoms of burnout to appropriate resources (3). In addition, group-based counseling or peersupport sessions may effectively address burnout and improve mental health during Covid-19.

\section{Leveraging digital technologies to prevent burnout}

In recent years, digital interventions are increasingly being used to improve health services and outcomes. One approach can be the balanced use of electronic health records to coordinate work schedules, monitor healthy work patterns, and address the risks of overburdening frontline healthcare providers during Covid-19. Counselling and interventions using digital platforms like mobile phones, apps, or internet-enabled devices can be an alternative option (9).

\section{Creating an enabling environment through organisational approaches}

It is essential to improve organisational measures to create a lasting impact on the work culture alongside interpersonal interventions, and address workplace stress. A meta-analysis found that organisation-directed interventions were associated with a medium reduction in burnout score (SMD $=-0.446 ; 95 \% \mathrm{Cl}$ :- $0.619-0.274$ ), while physician-directed interventions were associated with a moderate reduction in burnout score (SMD $=-0.178$; 95\% Cl: - 0.322 - 0.035) (3). Potential strategies include improving workflow management, organising services focusing on reducing workload, enhancing interoperability, arranging discussion and exchanging opinions, improving communication skills, provision for adequate rest and exercise, organising workshops on coping skills, and devising policies and practices for reducing burnout among health workforce during this pandemic(3, 9). These approaches may foster a supportive and enabling environment for healthcare providers. However, it is essential to include the healthcare provider in devising strategies for creating an enabling environment. A shared decision-making may assist in understanding potential challenges experienced by the providers, including the impacts of their participation or non-participation in Covid-19 responses on payroll or performance appraisal, operational challenges within and between hospital departments, individual and group psychosocial challenges that may affect the health workforce as well as health service delivery during this pandemic. 


\section{Conclusion}

Healthcare providers often experience occupational stress leading to burnout, which may be aggravated during Covid-19. While they work to fulfil their professional responsibilities, it is essential to recognise how workplace-related stress may affect their mental and emotional wellbeing. Such stressors may further impact resource-constrained contexts resulting in a severe paucity of healthcare providers. Furthermore, those stressors have profound ethical implications including moral distress, autonomy and welfare of the patient, and social justice, affecting health service delivery and maintenance of a healthy workforce in healthcare organizations during this pandemic. Evidence-based approaches for preventing burnout that have shown effectiveness in various contexts may help in identifying appropriate measures based on unique situations and available resources. Health policy makers and practitioners should adopt such interventions and develop context-specific approaches promoting a healthy workplace, addressing ethical issues, and preventing burnout among healthcare providers during the Covid-19 pandemic.

\section{Acknowledgments: None.}

Conflicts of interest and funding: The authors declare no funding or conflicts of interest.

Declaration: A preprint version of this commentary is available from:doi:10.31235/osf.io/4hxga

\section{References}

1. Imo UO. Burnout and psychiatric morbidity among doctors in the UK: A systematic literature review of prevalence and associated factors. BJPsych Bull. 2017 Aug; 41(4): 197-204.

2. Woo T, Ho R, Tang A, Tam W. Global prevalence of burnout symptoms among nurses: A systematic review and meta-analysis. J Psychiatr Res. 2020 Apr; 123: 9-20.

3. De Simone S, Vargas M, Servillo G. Organizational strategies to reduce physician burnout: a systematic review and meta-analysis. Aging Clin Exp Res. 2019 Oct 9:1-12.

4. Neely C. Physician burnout in the face of COVID-19. Bloomington, Minnesota:ICSI; 2020 Apr 23[cited 2020 Jun 3]. Available from: https:// www.icsi.org/icsi-news/news/physician-burnout-in-the-face-ofcovid-19/

5. Eadie W. Navigating nurse burnout in response to COVID-19. MedCity News. 2020 Apr 17[cited 2020 Jun 3]. Available from: https:// medcitynews.com/2020/04/navigating-nurse-burnout-in-response-tocovid-19/

6. Gavidia M. Sleep, physician burnout linked amid COVID-19 pandemic. AJMC News, 2020 Mar 20 [cited 2020 Apr 14]. Available from: https:// www.ajmc.com/newsroom/sleep-physician-burnout-linked-amidcovid19-pandemic
7. Chochinov A, Lim R. On the brink of burnout: COVID-19 and the ER. 2020 Mar; Canadian Association of Emergency Physicians. Available from: https://caep.ca/wp-content/uploads/2020/03/CAEP-Wellness-OpEd_ Final_Clean.pdf

8. Hossain MM, Sultana A, Purohit N. Mental health outcomes of quarantine and isolation for infection prevention: A systematic umbrella review of the global evidence. SSRN Electron J. 2020 Mar 26 [cited 2020 Apr 14]. Epub. DOI: 10.2139/ssrn.3561265.

9. Alessi C. Clinician burnout during the times of COVID-19. Healthcare IT News, 2020 Apr 3[cited 2020 Apr 14]. Available from: https://www. healthcareitnews.com/blog/europe/clinician-burnout-during-timescovid-19

10. Hossain MM, Tasnim S, Sultana A, Faizah F, Mazumder H, Zou L. Epidemiology of mental health problems in COVID-19: A review. PsyArXiv. 2020 May 28. Epub ahead of print. DOI: 10.31234/osf.io/q8e5u.

11. Sasangohar F, Jones SL, Masud FN, et al. Provider burnout and fatigue during the COVID-19 pandemic: Lessons learned from a high-volume intensive care unit. Anesth Analg. Epub ahead of print. 2020 Apr 9. DOI: 10.1213/ANE.0000000000004866.

12. Rios L. Mexican doctors attacked with bleach over coronavirus fears. Time. 2020 Apr 25[cited 2020 Jun 3]. Available from:https://time. com/5827496/mexico-doctors-coronavirus-attacks/

13. Semple K. 'Afraid to be a nurse': Health workers under attack during coronavirus pandemic. New York Times. 2020 Apr 27[cited 2020 Jun 3]. Available from:https://www.nytimes.com/2020/04/27/world/americas/ coronavirus-health-workers-attacked.html

14. Dzeng E, Wachter RM. Ethics in conflict: Moral distress as a root cause of burnout. J Gen Intern Med. 2020 Feb;35(2):409-11.

15. Shevell M. Health professional burnout: an (un)ethical consequence of modern health care? Can J Neurol Sci 2019;46(6):682-3. DOI: https://doi. org/10.1017/cjn.2019.280

.16. Teixeira C, Ribeiro O, Fonseca AM, Carvalho AS. Ethical decision making in intensive care units: A burnout risk factor? Results from a multicentre study conducted with physicians and nurses. J Med Ethics 2014 Feb; 40(2): 97-103. doi: 10.1136/medethics-2012-100619.

17. Wood G. What's behind the COVID-19 racial disparity? Atlantic. 2020 May 27[cited 2020 Jun 3]. Available from: https://www.theatlantic.com/ ideas/archive/2020/05/we-dont-know-whats-behind-covid-19-racialdisparity/612106/

18. Hipps RS. Are hospital ethics committees really necessary? J Med Humanit 1992 Fall; 13(3): 163-75. DOI: 10.1007/BF01127375.

19. Schreiber M, Cates DS, Formanski S, King M. Maximizing the resilience of healthcare workers in multi-hazard events: Lessons from the 2014-2015 Ebola response in Africa. Mil Med 2019; 184: 114-20.

20. Deldar K, Froutan R, Dalvand S, Gheshlagh RG, Mazloum SR. The relationship between resiliency and burnout in Iranian nurses: A systematic review and meta-analysis. Open Access Maced J Med Sci 2018 Nov $25 ; 6(11): 2250-6$.

21. Fessell D, Cherniss C. Coronavirus disease 2019 (COVID-19) and beyond: Micropractices for burnout prevention and emotional wellness. $J$ Am Coll Radiol. Epub. 2020 March 13. DOI: 10.1016/j.jacr.2020.03.013.

22. Suleiman-Martos N, Gomez-Urquiza JL, Aguayo-Estremera R, Canadas -De La Fuente GA, De La Fuente-Solana El, Garcia-Albendin L. The effect of mindfulness training on burnout syndrome in nursing: A systematic review and meta-analysis.J Adv Nurs; 76. Epub. 2020 Feb 5.DOI: 10.1111/ jan.14318

\section{Be a part of IJME}

IJME invites readers to submit research studies, comments, case studies, reports, reviews, letters, as also poems, short stories, original paintings and photographs of print quality ( both in colour and $\mathrm{B} / \mathrm{W}$ ) to be considered for publication.

All submitted matter is subject to peer review.

Contributors are neither paid nor charged any fee for published matter. 